\title{
ISOLASI DAN IDENTIFIKASI ZAT AKTIF EKSTRAK METANOL RIMPANG KUNYIT PUTIH (Curcuma mangga Val) FRAKSI ETIL ASETAT
}

\section{ISOLATION AND IDENTIFICATION OF ACTIVE COMPOUND METHANOL EXTRACT OF Curcuma mangga Val RHIZOMES OF ETHYL ACETATE FRACTION}

\author{
Kusmiyati $^{1}$, Nurfina Aznam ${ }^{2}$, Sri Handayani ${ }^{2}$ \\ Fakultas Farmasi Universits Ahmad Dahlan \\ Jl. Prof. Dr. Supomo, Yogyakarta, Telp (0274) 379418
}

\section{Abstrak}

Kunyit putih banyak mengandung zat aktif yang dimanfaatkan sebagai obat tradisional. Tujuan dari penelitian ini adalah untuk mengisolasi dan menentukan jenis zat aktif dari ekstrak metanol rimpang Kunyit Putih (Curcuma mangga Val) fraksi etil asetat serta menentukan kadar zat aktifnya. Sebanyak $1000 \mathrm{~g}$ kunyit putih halus dimaserasi dengan pelarut metanol pada suhu kamar selama 24 jam, disaring dan diulangi sebanyak 7x. Ekstrak metanol tersebut dipekatkan kemudian difraksinasi menggunakan etil asetat. Ekstrak etil asetat kental yang didapat sebanyak 39,05 g dipisahkan dengan Kromatografi Kolom Gravitasi (KKG). Senyawa hasil isolasi menggunakan KKG sebanyak 0,035g. Berdasarkan kesamaan dalam spektra UV-Vis dan GC-MS maka diduga senyawa zat aktif yang ada dalam ekstrak metanol kunyit putih fraksi etil asetat adalah senyawa Labda-8(17),12-dien-15,16-dial dengan kadar sebanyak 0,00149\%.

Kunci : $\quad$ isolasi, maserasi, fraksi etil asetet, kunyit putih

\footnotetext{
${ }^{2}$ Fakultas MIPA UNY
} 


\section{Abstract}

Curcuma mangga contains a lot of variety of active compound which use as traditional medicines. This research aimed to isolated and determinated the active compound of methanol extract Curcuma mangga rhizomes of ethyl acetate fraction and its rendemen. Amount of $1000 \mathrm{~g}$ curcuma mangga rhizomes was macerated with methanol solvent at room temperature for 24 hours. Remaceration was done seventh times. Methanol extract was fractionated with ethyl acetate. About 39,05 $\mathrm{g}$ of concentrated ethyl acetate fraction was then separated by Column Chromatography. According to the similarity of UV-Vis spectra and GC-MS, active compound in methanol extract Curcuma mangga rhizomes ethyl acetate fraction is predicted as Labda-8(17),12-dien-15,16-dial with rendemen amount of 0,00149\%.

Keyword : isolation, maceration, ethyl acetate fraction, Curcuma mangga

\section{PENDAHULUAN}

Indonesia merupakan negara yang kaya akan sumber daya alam hayati, diantaranya dengan dimilikinya hutan basah yang ditumbuhi dengan tanaman yang berkhasiat obat. Penggunaan tanaman obat atau lebih dikenal dengan obat tradisional sebenarnya sudah merupakan warisan nenek moyang. Hal itu dibuktikan dengan adanya jamu gendong, jamu godog, dan ramuanramuan yang masih digunakan sampai saat ini. Pengobatan tradisional saat ini sangat digemari. Hal ini dikarenakan banyaknya efek samping penggunaan obat-obat modern atau obat sintetik. Semakin berkembangnya ilmu pengetahuan menyebabkan orang sadar akan keunggulan bahan-bahan alam. Obat-obat tradisional tersebut, dalam kehidupan sehari-hari tidak dapat digunakan sebagai obat modern karena tidak dapat diresepkan sehingga perlu dilakukan penelitian lebih lanjut tentang kandungan kimia dari obat tersebut dan diuji secara klinis.

Tanaman kunyit putih (Curcuma mangga Val) merupakan salah satu dari sekian banyak tanaman obat tradisional di Indonesia. Rimpang kunyit putih dapat digunakan sebagai obat penambah nafsu makan, menguatkan syahwat, penangkal racun, penurun panas tubuh karena demam, pencahar, mengobati gatal-gatal, bronkhitis, asma, hingga radang yang disebabkan oleh luka. Di India, rimpang kunyit putih digunakan untuk obat masuk angin atau kembung, penguat lambung, pembangkit nafsu makan, memperbaiki pencernaan, dan penurun panas tubuh yang disebabkan oleh demam. Selain itu, rimpang kunyit putih juga digunakan untuk mengobati penyakit kulit, berupa bintik-bintik merah yang sangat gatal, dengan cara dibalurkan pada bagian kulit yang gatal tersebut (Fauziah, 1999).

Kunyit putih telah terbukti memiliki efek farmakologis yaitu memiliki 
sifat sebagai hemostatis (menghentikan pendarahan), menambah nafsu makan, antitoksik, dan mempercepat penyembuhan luka serta bermanfaat untuk menyembuhkan luka akibat kanker dan tumor. Kurkumin yang terkandung dalam rimpang kunyit putih bermanfaat sebagai antitumor dan anti-inflamasi (anti-radang). Sementara itu, saponin berkhasiat sebagai antineoplastik (antikanker) dan polifenol berfungsi sebagai antioksidan (Yellia, 2003).

Berdasarkan penelitian yang dilakukan oleh Abbas diketahui bahwa kunyit putih mempunyai 11 senyawa, yaitu campuran Stigmaterol dan $\beta$-sitosterol, Demetoksikurkumin, bismetoksikurkumin, 1,17-bis (4hidroksifenil)-1,4,6-heptatrien-3-on, 7-hidroksi-6-metoksi kaumarin, Kurkumin, Zerumin B, Curcumanggosida, Asam-4-hidroksisinamik, Labda-8(17),12-diene,15,16-dial dan Calcalatarin A (Abbas, 2005)

Oleh karena itu maka dilakukan penelitian ini untuk mengetahui zat aktif jenis apa yang ada di dalam rimpang kunyit putih, mengingat bahwa zat aktif ini sangat banyak manfaatnya dalam kehidupan sehari-hari.

\section{METODE PENELITIAN}

\section{Bahan}

Sedangkan bahan-bahan yang digunakan adalah :Rimpang kunyit putih kering dan dihaluskan, Akuades, Kapas bebas lemak, Kertas saring bebas lemak, Etil asetat GR (E.Merck), Metanol teknis, Heksana teknis, Aseton GR (E. Merck), Kloroform GR (E. Merck), Plat silika $60 \mathrm{GF}_{254}$ Merck, Silika Gel $60 \mathrm{G}$ (200-400 Mesh)

Alat

Adapun alat-alatnya terdiri dari : Satu set evaporator Buchii, Alat-alat gelas, Neraca, Pipet volume, Satu set alat kromatografi kolom, Spektrofotometer IR (Shimadzu FTIR 8021 PC), Spektrofotometer UV-Vis (Shimadzu UV-1601 PC), Spektrofotometer GCMS, Lampu UV 254nm dan $366 \mathrm{~nm}$ Camac UV Cabinet II, Aluminium foil

\section{Jalannya Penelitian}

\section{Pemilihan Kunyit Putih}

Kunyit putih yang digunakan adalah yang sudah tua, kemudian dikeringkan tanpa dikuliti dan dihaluskan yang didapatkan dari daerah Yogyakarta.

2. Maserasi serbuk rimpang kunyit putih.

Sampel sebanyak $1000 \mathrm{~g}$ dimaserasi dengan metanol, pada suhu kamar selama 24 jam sebanyak 7 kali pengulangan kemudian disaring dengan kertas saring. Ekstrak yang diperoleh dikumpulkan menjadi satu dan diuapkan dengan evaporator sampai pekat, kemudian difraksinasi dengan etil asetat. Fraksinasi ini dilakukan dengan menggunakan corong pisah dengan volume ekstrak metanol : etil asetat $=1: 1$ dan dipisahkan antara fraksi metanol dan fraksi etil asetat. Fraksinasi ini dilakukan dengan $3 x$ pengulangan, total fraksi etil asetat diuapkan dengan evaporator. 


\section{Kromatografi lapis tipis (KLT)}

Optimasi fase gerak dilakukan dengan menggunakan KLT dengan berbagai perbandingan antara kloroform dan heksana. Berdasarkan hasil dari perbandingan volume yang dipakai dalam kromatografi lapis tipis maka dipilih eluen dengan perbandingan volume kloroform: heksana $=4: 6$. Perbandingan ini dipilih karena harga $\mathrm{Rf}$ yang diberikan $=0,2$. Setelah eluen naik sampai batas atas $(0,5 \mathrm{~cm}$ dari ujung atas plat silika gel), plat silika gel diambil dari bejana dan dikeringkan di udara. Selanjutnya dideteksi dengan lampu UV pada $254 \mathrm{~nm}$.

\section{Kromatografi kolom}

Silika gel 60 (230-400 mesh) sebanyak 20 gram diaktifasi dengan pemanasan dalam oven selama 2 jam pada suhu $110^{\circ} \mathrm{C}$, selanjutnya didinginkan dengan meletakkannya dalam eksikator. Kolom mula-mula diisi glasswool pada bagian bawah dan menggunakan eluen yang digunakan pada KLT. Untuk pembuatan bubur, silika gel yang telah diaktifasi dimasukkan dalam beker gelas dan ditambahkan eluen yang sesuai dengan kromatografi lapis tipis, diaduk hingga homogen dan tidak ada gelembung udara. Selanjutnya diisikan ke dalam kolom yang sudah disiapkan. Cuplikan (fraksi etil asetat sebanyak 7,5 g) diimpregnasi pada silika gel yang lain, kemudian silika gel impregnasi ini dimasukkan ke dalam kolom, kran sedikit dibuka dan eluen ditampung. Selanjutnya baru ditambah eluen yang banyak untuk elusi. Setiap 5-10 mL eluat ditampung dalam botol sampel. Masing- masing botol (eluat) dianalisis dengan metode kromatografi lapis tipis. Kolom dihentikan jika pada plat KLT sudah tidak terdapat bercak noda. Eluat yang mempunyai harga $\mathrm{Rf}$ yang sama dan bercak yang sama dikumpulkan sebagai fraksi yang sama, dan selanjutnya dievaporasi. Hasil evaporasi kemudian dilakukan uji kemurnian, yaitu melakukan KLT dengan berbagai macam pelarut, jika dari berbagai macam pelarut tersebut menghasilkan satu noda berarti senyawa tersebut sudah murni, jika senyawa tersebut belum murni maka hasil uji murni ini bisa digunakan sebagai eluen untuk kromatografi kolom selanjutnya.

5. Identifikasi struktur senyawa zat aktif hasil kromatografi kolom.

Identifikasi struktur zat aktif hasil kromatografi kolom dilakukan dengan dengan menggunakan kromatografi lapis tipis dan spektroskopi UV-Vis, IR dan GC-MS

\section{Perhitungan Kadar Zat Aktif}

Berat senyawa hasil isolasi

Kadar zat aktif $=\frac{\text { Berat senyawa hasil isolasi }}{\text { Berat bahan awal }} \times 100 \%$

\section{Teknik Analisis Data}

Analisis yang digunakan dalam penelitian ini adalah:

Deskripsi dari bentuk struktur zat aktif yang dianalisis dengan menggunakan spektroskopi UV-Vis, IR, dan GC-MS 


\section{HASIL DAN PEMBAHASAN}

\section{Hasil Pemisahan Maserasi dan Fraksinasi}

Kunyit putih halus sebanyak 1000 g, dimaserasi dengan metanol dan didapatkan ekstrak kental metanol 358,56 g. Ekstrak metanol difraksinasi dengan etil asetat dan didapatkan ekstrak eluen untuk pemisahan kromatografi kolom selanjutnya.

3. Hasil Pemisahan dengan Kromatografi Kolom Gravitasi

Fraksi etil asetat dilakukan kromatografi kolom sebanyak $3 \mathrm{x}$, hasil kromatografi kolom secara umumnya dapat dilihat pada Tabel I.

Tabel I. Hasil kromatografi kolom ekstrak metanol kunyit putih fraksi etil asetat.

\begin{tabular}{|c|c|c|c|c|c|}
\hline $\begin{array}{c}\text { Kromatografi } \\
\text { kolom ke }\end{array}$ & Total fraksi & $\begin{array}{c}\text { Fraksi yang } \\
\text { diambil }\end{array}$ & Berat & Pelarut & Rf \\
\hline 1 & 137 & $109-137$ & $0,298 \mathrm{~g}$ & $\mathrm{~K}: \mathrm{H}=4: 6$ & 0,825 \\
\hline 2 & 69 & $57-66$ & 0,160 & $\mathrm{~K}: \mathrm{H}=4: 6$ & 0,525 \\
\hline 3 & 18 & $1-8$ & 0,035 & $\mathrm{E}: \mathrm{H}=2: 8$ & 0,45 \\
\hline
\end{tabular}

Keterangan: $\mathrm{K}=$ kloroform, $\mathrm{H}=$ Heksana, $\mathrm{E}=$ Etil asetat

kental fraksi etil asetat 39,05 g, dan diambil 7,5 g untuk kromatografi kolom.

\section{Hasil Kromatografi Lapis Tipis}

Kromatografi lapis tipis digunakan untuk mencari eluen untuk kromatografi kolom dan untuk uji murni, dari hasil KLT ini dapat diketahui eluen yang memberikan pemisahan yang baik. Berdasarkan hasil KLT maka eluen untuk kromatografi kolom 1 adalah perbandingan antara kloroform:heksana $=$ 4:6. Eluen dari kromatografi kolom 2 adalah perbandingan antara kloroform: heksana = 4:6. Eluen untuk kromatografi kolom 3 adalah etil asetat : heksana $=2: 8$. Perbandingan tersebut didapatkan dari hasil optimasi fase gerak dan yang memberikan nilai $\mathrm{Rf}=0,2$. Hasil kromatografi kolom 1 belum mendapatkan senyawa murni, berdasarkan hasil uji murninya, dari uji murni ini maka dapat juga digunakan sebagai
Rincian dari tiap-tiap kromatografi kolom yaitu : pada kromatografi kolom pertama didapatkan 137 fraksi, tiap-tiap fraksi dilakukan kromatografi lapis tipis, hasilnya dapat dilihat pada Tabel II. Pengoloman kedua didapatkan 69 fraksi, hasil analisis dengan kromatografi lapis tipis dari tiap fraksi dapat dilihat pada Tabel III. Pengoloman yang ketiga didapatkan 18 fraksi, hasil analisis dengan kromatografi lapis tipis dapat dilihat pada Tabel IV. Pengelompokan fraksi-fraksi ini didasarkan pada kesamaan Rf. Kadar zat aktif yang didapatkan $0,00149 \%$.

\section{Hasil Spektroskopi UV-Vis}

Hasil kromatografi kolom yang sudah murni kemudian dilakukan analisis dengan spektroskopi UV-Vis, spektra UV-Vis dari ekstrak metanol kunyit putih fraksi etil asetat dapat dilihat pada Gambar 1 . 


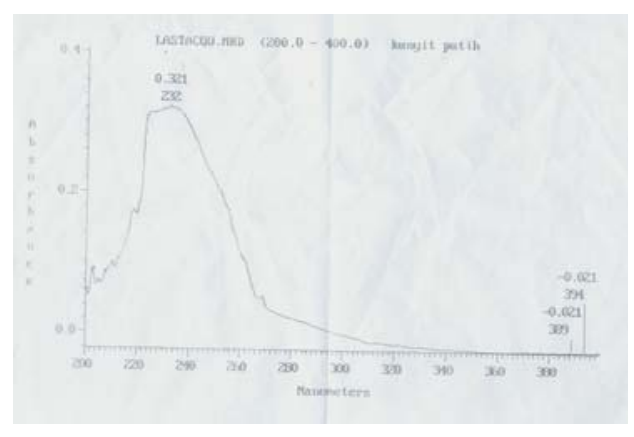

Gambar 1. Spektra UV-Vis isolat ke 1-8

Spektra UV-Vis dari senyawa zat aktif dalam fraksi etil asetat kunyit putih menunjukkan panjang gelombang maximum $\left(\lambda_{\max }\right) 232 \mathrm{~nm}$, hal ini menunjukkan bahwa dalam senyawa ini terdapat gugus kromofor dan $\mathrm{C}-\mathrm{H}$ alifatik.

Senyawa dalam kunyit putih pada $\lambda_{\max } 234 \mathrm{~nm}$ merupakan senyawa Labda-8(17),12-dien-15,16-dial, (Faridah, 2005) data kesamaan senyawa standar dengan senyawa hasil isolasi mengenai $\lambda_{\max }$ tersebut dapat dilihat pada Tabel V.

Tabel II. Hasil kromatografi kolom pertama

\begin{tabular}{|l|l|}
\hline \multicolumn{1}{|c|}{ No fraksi } & \multicolumn{1}{c|}{ Keterangan pada plat KLT } \\
\hline $1-17$ & Terdapat banyak noda, nodanya lebih tebal \\
\hline $18-29$ & Terdapat banyak noda yang lebih tipis \\
\hline $30-55$ & Terdapat banyak noda \\
\hline $31-73$ & Terdapat banyak noda \\
\hline $74-91$ & Tidak ada noda, tetapi batas atas plat kotor \\
\hline $100-108$ & Terdapat satu noda tetapi bagian atasnya kotor sekali \\
\hline $109-137$ & Terdapat satu noda dan bagian atasnya lebih bersih \\
\hline
\end{tabular}

Tabel III. Hasil kromatografi kolom kedua

\begin{tabular}{|l|l|}
\hline \multicolumn{1}{|c|}{ No fraksi } & \multicolumn{1}{c|}{ Keterangan pada plat KLT } \\
\hline $1-36$ & Tidak dielusi \\
\hline $37-56$ & Terdapat dua noda \\
\hline $57-66$ & Terdapat satu noda dan atasnya lebih bersih \\
\hline $67-69$ & Terdapat satu noda tetapi bagian atasnya lebih kotor \\
\hline
\end{tabular}

Tabel IV. Hasil kromatografi kolom ketiga

\begin{tabular}{|l|l|}
\hline \multicolumn{1}{|c|}{ No fraksi } & \multicolumn{1}{c|}{ Keterangan pada plat KLT } \\
\hline $1-18$ & Satu noda dengan sedikit ekor \\
\hline
\end{tabular}


Tabel V. $\lambda_{\max }$ dari senyawa standar dan hasil isolasi

\begin{tabular}{|l|c|}
\hline \multicolumn{1}{|c|}{ Senyawa } & $\lambda \max (\mathbf{n m})$ \\
\hline $\begin{array}{l}\text { Labda-8(17),12-dien-15,16- } \\
\text { dial literatur }\end{array}$ & 234 \\
\hline Hasil isolasi (puncak no 15) & 232 \\
\hline
\end{tabular}

5. Hasil Spektra Infra Merah isolat no 1-8

Spektra Infra Merah isolat no 1-8 dapat dilihat pada Gambar 2.

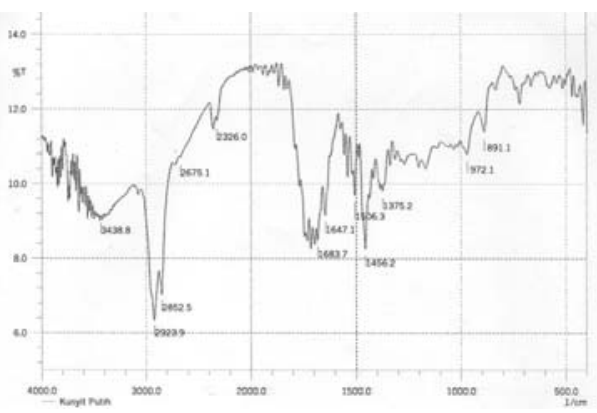

Gambar 2. Spektra Infra Merah isolat no 1-8
Hasil dari spektra IR dari fraksi etil asetat kunyit putih menunjukkan adanya gugus $\mathrm{C}-\mathrm{H}$ alifatik yaitu dengan adanya serapan pada daerah 2923,9$2852,5 \mathrm{~cm}^{-1}$ Adanya gugus $\mathrm{C}=\mathrm{O}$ karbonil yaitu adanya serapan pada daerah 1683,7 $\mathrm{cm}^{-1}$ dan gugus $\mathrm{C}=\mathrm{C}$ alkena yaitu adanya serapan pada daerah $1647,1 \mathrm{~cm}^{-1}$. Serapan di dearah $1375,2 \mathrm{~cm}^{-1}$ merupakan gugus $\mathrm{CH}_{2}$ bengkokan. Kemungkinan spektra IR dalam senyawa ini mengandung gugus fungsi $\mathrm{C}-\mathrm{H}$ aldehida, $\mathrm{C}=\mathrm{O}$ karbonil tipe aldehida dan $\mathrm{C}=\mathrm{C}$ alkena.

\section{Kromatogram GCMS}

Hasil analisis dengan kromatografi gas-spektroskopi massa menunjukkan adanya 26 puncak, ini menunjukkan bahwa dalam sampel masih terdapat banyak senyawa. Intensitas dari 26 puncak tersebut dapat dilihat pada Gambar 3.

Hasil analisis GCMS ada 26 puncak tetapi dalam Spektroskopi Massanya hanya diambil 6 puncak

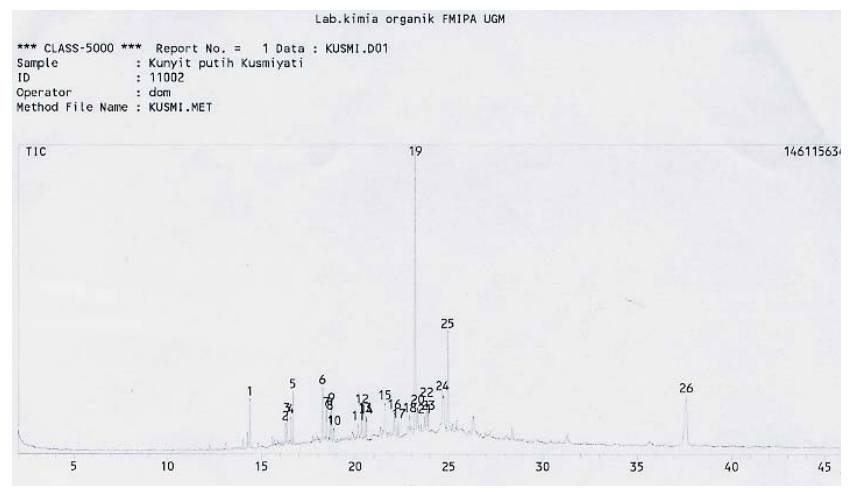

Gambar 3. Kromatogram GC-MS isolat no 1-8 
dominan saja. Hasil dari 6 puncak dominan tersebut dapat dilihat pada Tabel VI. pada spesies Candida Albicans, C. Kruseii, C. Parapsilopsis (Geofrey et, al. 1998). Spektra massa dari senyawa hasil

Tabel VI. Puncak dominan hasil analisis GC-MS

\begin{tabular}{|c|c|l|c|c|}
\hline No puncak & $\mathbf{t}_{\mathbf{R}}$ & \multicolumn{1}{|c|}{ Perkiraan senyawa } & Kadar (\%) & SI \\
\hline 1 & 14,392 & Dodekana & 2,11 & 96 \\
\hline 2 & 16,300 & Longipinenoksida & 1,47 & 83 \\
\hline 6 & 18,267 & Nerolidol isomer & 7,53 & 78 \\
\hline 15 & 21,592 & Labda-8(17),12-dien-15,16-dial & 7,00 & \\
\hline 19 & 23,225 & Dioktil ptalat & 19,34 & 93 \\
\hline 25 & 24,958 & 9-oktadekenamia & 6,59 & 90 \\
\hline
\end{tabular}

Hasil GC menunjukkan adanya 26 puncak, ini menunjukkan bahwa pe- isolasi pada puncak 15 dapat dilihat pada Gambar 4.

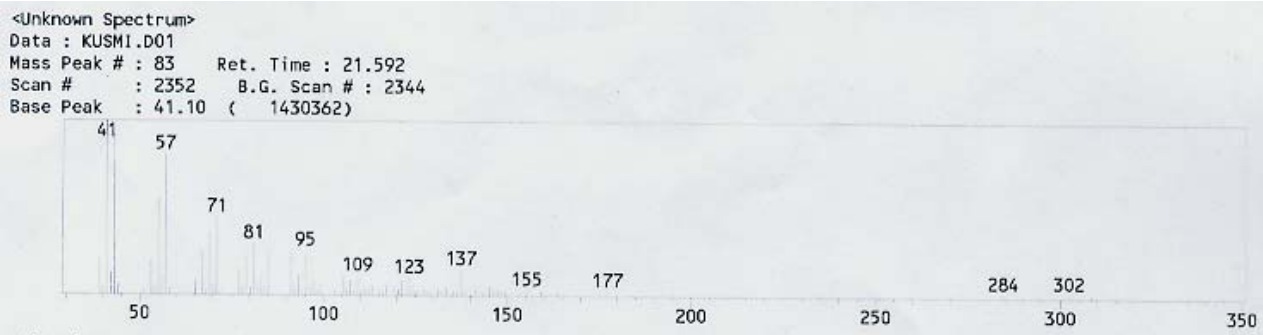

Gambar 4. Spektrum Massa Puncak no 15

misahan yang dilakukan dengan kromatografi kolom belum sempurna karena masih terdapat banyak senyawa, yang ditunjukkan dengan adanya banyak puncak. Analisis dengan Spektroskopi Massa hanya 6 puncak tertinggi yang ditampilkan. Berdasarkan spektra massa yang dihasilkan maka dapat diketahui senyawa yang termasuk dalam kelompok zat aktif adalah pada puncak no 15 , yang diduga adalah senyawa Labda-8(17), 12-dien-15,16-dial. Senyawa ini terbukti mempunyai aktifitas anti jamur, yaitu
Perbandingan spektra massa dari senyawa hasil isolasi dengan senyawa Labda-8(17),12-dien-15,16-dial dapat dilihat pada Tabel VII.

Hasil spektroskopi UV-Vis senyawa Labda-8(17), 12-dien- 15,16-dial ini mempunyai $\lambda_{\text {maks }} 234 \mathrm{~nm}$. Hasil spektroskopi Infra Merah dari senyawa ini menunjukkan adanya serapan pada daerah $2950 \mathrm{~cm}^{-1}, 1730 \mathrm{~cm}^{-1}$ (menunjukkan adanya gugus aldehida), 1680 $\mathrm{cm}^{-1}$ (menunjukkan adanya $\mathrm{C}=\mathrm{C}$ alkena). 
Tabel VII. Perbandingan spektra massa senyawa hasil isolasi dengan literatur

\begin{tabular}{|l|l|}
\hline \multicolumn{1}{|c|}{ Senyawa } & \multicolumn{1}{c|}{ Fragmentasi (m/z) } \\
\hline Labda-8(17),12-dien-15,16-dial & {$[41], 55,69,81,95,109,123,137,177,284,302(\mathrm{M}+)$} \\
\hline Senyawa hasil isolasi & {$[41], 57,71,81,95,109,123,137,155,177,284,302(\mathrm{M}+)$} \\
\hline
\end{tabular}

Senyawa hasil isolasi ini mempunyai berat molekul 302. Puncak fragmen pada $\mathrm{m} / \mathrm{z} 177$ didapatkan dari pelepasan $\mathrm{C}_{7} \mathrm{H}_{9} \mathrm{O}_{2}$. Puncak fragmen pada $\mathrm{m} / \mathrm{z} 137$ didapatkan dari fragmen pada $\mathrm{m} / \mathrm{z} 177$ dengan pelepasan $\mathrm{C}_{3} \mathrm{H}_{4}$. Puncak fragmen pada $\mathrm{m} / \mathrm{z} 123$ didapatkan dari fragmen $\mathrm{m} / \mathrm{z} 137$ dengan pelepasan $\mathrm{CH}_{2}$. Puncak fragmen pada m/z 109 didapatkan dari fragmen $\mathrm{m} / \mathrm{z} 123$ dengan mengalami fragmen pada $\mathrm{m} / \mathrm{z} 71$ didapatkan dari fragmen $\mathrm{m} / \mathrm{z} 137$ dengan mengalami pelepasan $\mathrm{C}_{5} \mathrm{H}_{6}$. Puncak fragmen pada $\mathrm{m} / \mathrm{z} 57$ didapatkan dari fragmen $\mathrm{m} / \mathrm{z} 71$ dengan mengalami pelepasan $\mathrm{CH}_{2}$. Puncak fragmen pada $\mathrm{m} / \mathrm{z} 41$ yang merupakan puncak dasar didapatkan dari fragmen $\mathrm{m} / \mathrm{z} 57$ dengan mengalami pelepasan $\mathrm{CH}_{4}$. Pola fragmentasi dari senyawa ini dapat dilihat pada Gambar 5.

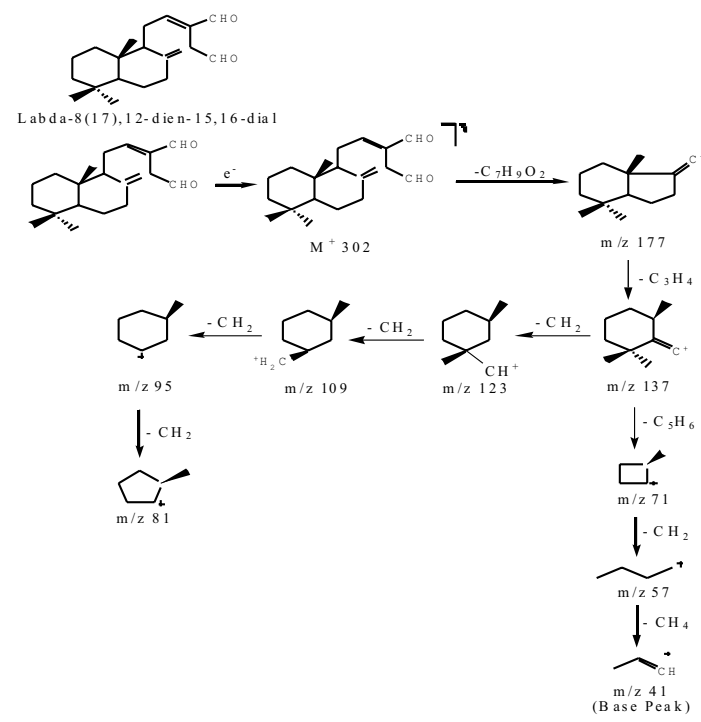

Gambar 5. Pola Fragmentasi Senyawa Labda-8(17),12-dien,15,16-dien

pelepasan $\mathrm{CH}_{2}$. Puncak fragmen pada $\mathrm{m} / \mathrm{z} 95$ didapatkan dari fragmen m/z 109 dengan pelepasan $\mathrm{CH}_{2}$. Puncak fragmen pada $\mathrm{m} / \mathrm{z} 81$ didapatkan dari fragmen $\mathrm{m} / \mathrm{z}$ 95 dengan pelepasan $\mathrm{CH}_{2}$. Puncak
Berdasarkan kesamaan dari data dalam spektroskopi UV-Vis, IR dan GC-MS maka diperkirakan senyawa aktif hasil isolasi dalam ekstrak metanol rimpang kunyit putih fraksi etil asetat 
adalah senyawa Labda-8(17),12dien-15,16-dial.

\section{KESIMPULAN}

Berdasarkan hasil penelitian dan pembahasan dapat disimpulkan sebagai berikut:

1. Jenis zat aktif yang diduga terkandung dalam ektrak metanol rimpang kunyit putih fraksi etil asetat berdasarkan analisis UV-Vis,IR dan GC-MS adalah Labda-8(17),12-dien-15,16-dial.

2. Kadar Labda-8(17),12-dien-15,16-dial yang dapat diisolasi dari ekstrak metanol rimpang kunyit putih fraksi etil asetat adalah $0,00149 \%$

\section{DAFTAR PUSTAKA}

Faridah Abbas Farida. (2005). Phytocemical and Biologycal Activity Studies of Cosmos Caudatus and Curcuma Mangga and the online Characterization of Bioactive Fraction from Melicope Ptelefolia. Disertation, Uni P.M. Malaysia.

Fauziah Muhlisah.(1999). Temu-temuan dan Empon-emponan. Budidaya dan Manfaatnya. Penerbit Kanisius, Yogyakarta.

Geissman, T.A.(1962). The Chemistry of Flavonoid Compounds. New York: The macmillan Company, New York.
Harborne, JB.(1987). Metode fitokimia Penuntun cara Modern Menganalisa Tumbuhan. (terjemahan, Kosasih Padmawinata). ITB (Buku asli 1984). Bandung.

Hardjono Sastrohamidjojo.(2001). Spektroskopi. Edisi 2. Liberty. Yogyakarta.

Hardjono Sastrohamidjojo. (1998). Kromatografi. Liberty. Yogyakarta.

Hostettman, K., Hostettman, M., dan Marston, A. (1995). Cara Kromatografi Preparatif Penggunaan pada Isolasi Senyawa Bahan Alam. (terjemahan, Kosasih P.). ITB (Buku asli:1986). Bandung.

Markham, K.R.(1988). Cara Mengidentifikasi Flavonoid. (terjemahan, Kosasih Padmawinata). ITB(Buku asli:1982). Bandung.

Sri Rahayu.(1997). Ekstraksi dan Identifikasi Senyawa Alkaloid Dalam Rimpang Kunyit Mangga (Curcuma Zedoaria (Berg) Roscoe), Laporan Penelitian Jurusan Pendidikan Kimia FMIPA IKIP Yogyakarta.

Yellia Mangan.(2003). Cara Bijak Menaklukkan Kanker. Agromedia Pustaka. Jakarta. 